\title{
Sonoplastia: breve percurso de um conceito
}

\author{
CÉSAR LIGNELLI ${ }^{1}$
}

1 Professor da Área de Voz e Performance do Departamento de Artes Cênicas (CEN), do Programa de Pós-Graduação em Artes (PPG-Arte) e do Programa de Pós-Graduação em Artes Cênicas (PPG-CEN) da Universidade de Brasília. É Pós- Doutorando em Cultura Contemporânea (PACC-UFRJ) 


\section{- RESUMO}

De modo geral, o presente artigo aborda reflexões envolvendo visualidades e sonoridades da cena. Especificamente abarca um percurso de pesquisa iniciado formalmente em 2004, e ainda em andamento, acerca do conceito de sonoplastia e de suas possibilidades de produção de sentido em performance. Nessa perspectiva, para além da função referencial são destacadas instâncias dramáticas e discursivas passíveis de serem atribuídas à sonoplastia. Em forma de relato são apresentadas também definições de conceitos complementares como de música de cena, de palavra e de espacialização para subsidiar a exposição central.

\section{- PALAVRAS-CHAVE}

Sonoplastia, conceito, sentido.

\section{- ABSTRACT}

In general, this article addresses reflections involving visualities and sounds of the scene. Specifically covers a research path formally began in 2004 that is still in progress, about the concept of sonoplastia and its possibilities to produce sense in performance. In this perspective, beyond the referential function, the dramatic and the discursive instances that can be attributed to the sound effects are highlighted. Shaping as a report article presents complementary definitions for concepts such as music scene, word and spatialization to subsidize the central exhibition.

\section{- KEYWORDS}

Sonoplastia, concept, sense.

Ao deparar com as publicações derivadas de congressos e reuniões científicas da Associação Brasileira de Pesquisa e Pós-graduação em Artes Cênicas (ABRACE), se torna explicito o crescente interesse dos pesquisadores com relação a temas que abarquem relações entre as sonoridades e as visualidades presentes na cena em função do número e da diversidade de perspectivas dos artigos publicados que consideram o assunto ${ }^{2}$. No entanto são exíguos os resultados encontrados em língua portuguesa ao se buscar materiais resultantes de pesquisas que evidenciem discussões conceituais e de possibilidades de sentido advindos particularmente da sonoplastia na cena.

De modo geral, e com variáveis terminológicas podemos considerar que as sonoridades da cena envolvem palavra (falada ou cantada), música, sonoplastia e a organização dessas instâncias em um tempo/espaço específico no âmbito de 360 . Esta perspectiva têm sido o ponto de partida para a formação de atores e de resultados estéticos vinculados ao grupo de pesquisa "Vocalidade \& Cena"3.

Este artigo tem como foco justamente reflexões envolvendo inúmeras práticas relacionadas à sonoplastia. No entanto, apresentarei sinteticamente outras possibilidades acústicas da cena para então desenvolver particularidades da sonoplastia.

A palavra neste contexto é considerada como evento acústico, que se distingue da estaticidade da palavra escrita (cursiva, impressa ou advinda de telas de suportes digitais). Estas últimas estão relacionadas à representação gráfica da palavra (DAVINI 2006 e LIGNELLI 2007; 2008; 2009). Tal distinção pode parecer tautológica. No en-

\footnotetext{
2 Ver http://www.portalabrace.org/busca/

3 Formado atualmente por professores e estudantes de iniciação científica e pós-graduação da Universidade de Brasília e da Universidade Federal de Pernambuco.
} 
tanto, em minha experiência com a formação de atores onde o foco encontra-se na vocalidade reconheço o impacto da representação gráfica do texto na forma em que este é proferido. Esta influência apresenta-se principalmente como um condicionador da forma sonora, e muitas vezes o performer evidencia variáveis de intensidades, frequências, andamentos e acentos que não necessariamente condizem as atitudes e intenções a serem manifestadas pelos personagens e desejadas pela direção. Por outro lado; pelos espaços que a escrita apresenta, deixa uma liberdade considerável para sua performance, distinguindo-se assim da partitura musical que em comparação com palavra escrita explicita mais precisão no tocante à suas sonoridades.

Estas diferenças entre palavra dita e grafada por um lado e escrita e partitura por outro não são aqui proferidas com juízos de valor, mas suas peculiaridades são destacadas a fim de se enfatizar a necessidade de se delimitar estratégias para pensar a palavra como ato e seu efeito em contextos diversos.

Etimologicamente, música significa a arte das musas. Na gênese da palavra musa, encontra-se uma raiz indo-européia, na qual se fundem conceitos ancestrais de exultação, alegria, memória e pensamento. Assim, podemos sugerir que música pode estar relacionada, em suas origens, a uma espécie de arte das sensações e ou emoções. No entanto a música de cena apresenta uma distinção epistemológica básica com relação a música no sentido geral. Uma composição musical normalmente se basta como obra estética em si, enquanto que a música de cena apresenta como princípio de produção de sentido o diálogo com outras instâncias visuais e sonoras presentes na cena.

A seguir, serão apontadas acepções de música a partir de algumas referências relevantes no decorrer da história, a fim de averiguar modificações no tempo e culminar com uma definição música que contemple as peculiaridades da cena.

Segundo Jean-Jacques Rousseau (1712-1778), a música é "a arte de combinar os sons de uma forma agradável ao ouvido” (MICHEL, 1967, p. 423). Por estar estritamente vinculada ao gosto e à função de agradar, essa definição de música não contempla as necessidades da cena teatral, uma vez que o efeito almejado pode estar relacionado a variáveis distantes do agradável.

Émile Maximilien Paul Littré (1801-1881) define a música como a "ciência ou o emprego dos sons que se denominam racionais, quer dizer, que entram em uma estrutura denominada escala" (MICHEL, 1967, p. 423). Apesar da definição de Littré não estar diretamente atrelada ao gosto, ela desconsidera a organização musical por timbres, ritmos, intervalos, que não se configuram em escalas. Esse contexto também não considera a música eletrônica, aleatória, concreta e outras vertentes conceituais que não se organizam exclusivamente a partir de escalas de alturas e, portanto, resulta insuficiente.

Nos primeiros anos do século XX, as definições de música e, por consequência, de compositor, no Ocidente, apresentaram maior flexibilidade quanto à sua relação de dependência das alturas ou frequências definidas dos sons. No verbete do Oxford English Dictionary "Música é a arte de combinar sons visando à beleza da forma e a expressão das emoções; os sons assim produzidos; som agradável, por exemplo, o canto de um pássaro, o murmúrio de um riacho, o latido de cães" (1956). Em primeiro lugar, vale ressaltar que, para recorrer a essa definição, seria necessário revisar o conceito de beleza. No entanto, sua consideração permite esclarecer a posição a respeito da música como discurso musical, a partir da qual o canto de um pássaro ou 
o murmúrio de um riacho, em si, não comporta a ideia de discurso estético-musical a princípio.

Para Murray Schafer (1991, p. 187), música é "uma coleção dos mais excitantes sons concebidos e produzidos pelas sucessivas operações de pessoas que têm bons ouvidos". Assim, se ressalta o papel indispensável dos compositores, para organizar o discurso musical de acordo com os parâmetros estabelecidos em cada caso. No entanto, tal definição limita o ato de compor a um grupo restrito e por outro lado, os efeitos requeridos na cena também não se restringem a excitar.

Para Lívio Tragtenberg, a música engloba "todo e qualquer evento sonoro originário de qualquer espécie de fonte sonora que possa ser transmitida ao sistema nervoso central através de variação da pressão do ar, o que abarca, portanto, tanto os chamados sons musicais como os chamados ruídos de qualquer espécie" (1999:26). No entanto, a formulação de Tragtenberg, apesar de sua precisão e abrangência, não explicita o papel das imprescindíveis operações discursivas efetuadas pelos compositores para a cena. De fato, sons de diversas ordens nem sempre constituem em discurso musical definido ou coerente com a cena.

Considerando as definições transcritas anteriormente compreendo que a música de cena pode ser caracterizada por composições organizadas a partir de sons advindos de qualquer fonte que afetem o sistema nervoso humano, incluindo palavra e sons referenciais desde que estes se encontrem deslocados de seu uso habitual em um dado contexto. É imprescindível que ocorra em tempo e espaço específico e exerça na circunstância funções gerais de reforço e/ou contraponto e suas variáveis discursivas na cena.

O desenho acústico ou a espacialização estão relacionados aos motivos e ao modo pelo qual a palavra, a música e a sonoplastia são apresentadas à audiência. Estas podem ocorrer a partir de fontes humanas, não humanas e híbridas, de forma mecânica e/ou técnica.

A mecânica (humana, não humana e híbrida) ocorre com o deslocamento da fonte sonora no espaço. Ou seja, quando um ator fala ou canta em cena andando ou correndo há uma espacialização mecânica humana. Se um ator atravessa o palco com uma caixa de som ligada acontece nessa perspectiva uma espacialização mecânica não humana, uma vez que a fonte é a caixa de som. No entanto, se um performer vai em direção à plateia tocando um saxofone podemos dizer que a espacialização é mecânica hibrida uma vez que apesar da fonte ser o instrumento de sopro ele só produz som em função de uma intervenção direta humana.

Já a espacialização técnica humana se dá com alterações controladas de parâmetros do som que simulem a movimentação do som e da respectiva fonte sonora no espaço. Por exemplo, um ator pode estar parado, mas ao modular a intensidade de um som contínuo de fraco a fortíssimo dá a impressão de que esse som, junto a fonte que o produziu estava distante, se aproximou e invadiu o espaço.

Por outro lado, a espacialização técnica não humana pode se dar com meios analógicos desde um potenciômetro de volume associado a um sistema mono até com o auxílio de mesas de som, onde distintos canais e caixas de som podem estar conectados permitindo a movimentação do som no espaço. A espacialização técnica também pode ocorrer digitalmente a partir do uso de hardwares associado a softwares que permitam a movimentação do som no espaço.

Por fim a espacialização técnica híbrida se dá com a produção sonora humana 
ao vivo direcionada artificialmente a partir de interfaces analógicas ou digitais. Por exemplo, um ator ao cantar parado em cena pode ter sua voz passeando pelo espaço através de caixas de som localizadas em pontos estratégicos, ou ter em sua voz processamentos diversos de reverberação e chorus por exemplo.

Além da direcionalidade e do movimento, pode-se propiciar às audiências a sensação de alteração na percepção das dimensões do espaço arquitetônico em que a performance é realizada também por meio da manipulação de parâmetros do som. Como fenômenos essencialmente perceptivos, os parâmetros sonoros quanto a nossa percepção são relativos. Ou seja, é mais sensato afirmar que um som possui determinada qualidade com a referência de outro som para relacioná-lo; este princípio também se aplica às intensidades em suas gradações entre fraquíssimo e fortíssimo; às frequências entre os sons mais graves e mais agudos percebido por nossos ouvidos; timbres com suas qualidades mais ou menos claras, metálicas, escuras etc. e até nas funções harmônicas onde cada acorde é qualificado, quanto a sua função, em relação ao acorde precedente e ao subsequente. O mesmo ocorre ainda com relação à movimentação do som no espaço, que pode ser percebida com mais clareza se relacionada a referenciais fixos. No entanto, as possibilidades do desenho acústico da cena dependem das técnicas e tecnológicas disponíveis em associação às requeridas pela obra, grupo e/ou diretor.

Enfim a sonoplastia, foco do presente artigo, será delimitada na tentativa de compreender os sons de performances teatrais que não pertençam a palavra nem se constituem em música de cena propriamente dita, apesar de afetarem diretamente a produção de sentido da cena e poderem ser desenhadas acusticamente. A seguir serão consideradas características da sonoplastia a partir de referências de obras de Lívio Tragtenberg e Roberto Gil Camargo a fim de embasar o desenvolvimento do tema.

Tragtenberg define sonoplastia como "um som inserido na cena que não sofre interferência de um compositor e nem deslocamento em relação ao seu contexto referencial. Ou seja, a escolha desse som não apresenta outra intenção com relação ao seu uso que não seja a ilustração" (1999:91). De fato, a função ilustrativa que pode exercer a sonoplastia da cena é indiscutível, contudo essa definição contempla estritamente a ilustração, que da perspectiva a ser proposta constitui-se em apenas um dos modos de suas possibilidades.

Por outro lado, para Camargo, que parece ter escrito até o momento o único livro em língua portuguesa que trata estritamente do assunto, a sonoplastia é ao mesmo tempo uma técnica e um processo de criação realizado em diferentes etapas. A primeira etapa consiste no levantamento prévio dos elementos sonoros que serão postos em cena com base nas rubricas do autor e/ou pela direção teatral. A segunda etapa consiste na seleção, considerando o porquê do som, a intenção do diretor ao empregar determinado efeito, o que estes sons podem representar no contexto e estrutura da peça. A terceira etapa refere-se à produção de sons. A quarta à adequação, ordenação de material, considerando a coerência e o bom gosto. A quinta consiste na relação entre a sonoplastia e os outros elementos da cena. A sexta refere-se à operação propriamente dita (1986, p. 9-14).

As etapas de trabalho do sonoplasta indicadas por Camargo parecem bem delineadas pelo autor, demonstrando domínio e reflexão sobre o tema. Contudo, quando afirma que o bom gosto é requisitado ao sonoplasta, acredita-se que o autor refira-se à necessidade de senso estético do sonoplasta para com a proposta da cena, uma 
vez que parece ser interessante evitar juízo valor atrelado à arbitrariedade do gosto na abordagem de experiências estéticas. Ou seja, o bom gosto, a princípio, pode servir a uma e/ou algumas estéticas a qual tenha afinidade de gosto, enquanto o senso estético pode constituir-se em um termo que dá conta mais amplamente da composição do sonoplasta ao se pensar nas distintas demandas estéticas as quais ele pode estar a serviço na cena contemporânea.

Quanto à execução da sonoplastia reproduzida mecanicamente ou executada ao vivo Camargo se posiciona afirmando que com todos os recursos disponíveis, a sonoplastia ao vivo ainda é a forma ideal, a mais perfeita por se ajustar plenamente à natureza do teatro, que é uma arte que se realiza ao vivo, na presença do espetáculo, ao contrário da gravação, que soa sempre como um recurso artificial. Considera que a percussão ao vivo seja um recurso mais dificultoso e oneroso e que a contratação de músicos profissionais sempre encarece a produção, uma vez que demanda muitas horas de ensaio para se obter a integração perfeita entre música e cena, respeitando e acompanhando o ritmo e a evolução do espetáculo. Já a desvantagem da sonoplastia reproduzida mecanicamente reside em que o som gravado nunca reproduz fielmente a percussão ao vivo (1986, p. 11-12).

Camargo aponta problemas com relação à sonoplastia executada ao vivo e à reproduzida mecanicamente, uma vez que considera a primeira muito onerosa e a segunda de baixa fidelidade. Afirmativas problematizáveis. Levando em conta o contexto histórico em que escreveu o livro é possível compreender que o autor refira-se à baixa qualidade dos equipamentos de som que frequentemente têm equipado os teatros brasileiros.

Por outro lado, o custo e a qualidade tanto da sonoplastia executada ao vivo quanto da reproduzida mecanicamente depende de muitos fatores, como por exemplo, dos equipamentos requeridos e do grau complexidade de cada proposta. Também a comparação entre o tempo utilizado para o ajuste da sonoplastia ao vivo à cena e a reproduzida mecanicamente podem ser relativizadas. $\mathrm{O}$ autor desconsidera os procedimentos de seleção, captação, ensaio, edição e espacialização dos processos composicionais a serem reproduzidos mecanicamente, que podem também demandar muito tempo de que quem os produz e exigem uma série de conhecimentos cênicos, técnicos e musicais. Ainda as possibilidades percussivas expostas pelo autor para produção de efeitos para a cena são extensas, mas restritas ao compará-las às possibilidades disponíveis na contemporaneidade.

Ao considerar que Camargo confere à sonoplastia ao vivo o lugar de forma ideal e mais perfeita por se ajustar à natureza do teatro, questiona-se: Ideal e perfeito para quem, para que e em que contexto histórico? Ideal e perfeito para que teatro? Ainda nessa discussão sobre o tema da música ao vivo ou reproduzida mecanicamente e o que produzem na cena, tornam-se relevantes considerações envolvendo 'presença versus ausência' e 'incorporação versus desincorporação' quando a produção das sonoridades e visualidades da cena bem como a recepção sofrem interferências diretas dos meios audiovisuais de produção e reprodução. Explicitando: músicos em cena produzem sentido em si e nem sempre essa presença serve à proposta estética em questão.

Hoje entendo por sonoplastia todo o som de origem referencial (não caracterizado como palavra nem como música) que se encontre no uso habitual em um dado contexto, produzido para e/ou na cena teatral, que além de sua função referencial, pode exercer funções dramáticas e discursivas, onde se incluem ainda sons não pré-estabelecidos como algumas manifestações da plateia (tosses, interjeições, risadas), dos atores (queda 
de objetos de cena, trocas de figurinos), fenômenos naturais (ventos, chuvas e trovões) e demais sons externos ao local (buzinas, passeatas, shows) que podem afetar a cena.

Naturalmente dependendo do espaço escolhido para a performance, como por exemplo a rua, os sons não pré-estabelecidos normalmente possuem tal intensidade e constância que os atores em toda a sua produção corporal (vocal e cinética) precisam considerar e dialogar o tempo todo com a interferência desses sons na cena.

Como exemplo das funções da sonoplastia citadas acima se pode considerar o som de um sino de igreja em uma cena hipotética que se passa em uma cidade brasileira do interior. Este tem origem e a princípio uma função também referencial. A recepção, ao ouvir o referido som, vai se dar conta que este advém de um possível campanário de uma igreja que se localiza numa direção específica com relação a cena. Mesmo que este som não tenha sido produzido anteriormente para a cena ele interfere nela, uma vez que é percebido e passa a fazer parte da produção de sentido na performance em alguma instância. Porém, no caso do som de sino de igreja, se ele foi concebido para a cena, provavelmente além da função referencial também desempenhe uma função discursiva, pois juntamente à alusão da existência do prédio da igreja perto ou no contexto da cena, faz menção ao controle do tempo marcado pelo número de badalados do sino, aos valores morais e cristãos que atravessam os personagens e ainda a delimitação desse espaço de controle pela igreja expressos por até onde o som deste sino abarque. Se este mesmo som de sino de igreja constituir-se no contexto da cena como motor da ação que se segue, como por exemplo, na situação hipotética do personagem de um Pai alcoolizado de um recém-nascido que vai reclamar ao Padre da igreja que o sino acorda e estressa o bebe durante vários momentos do dia. O Pai exige que o sino pare de tocar. O Padre diz que não pode deixar de fazer soar o sino. Os dois discutem e não se entendem. O Pai saca uma arma e dispara cinco tiros contra o Padre. Nesse caso, o som do sino da igreja também possui função dramática uma vez que influenciou diretamente na ação da cena.

A definição das sonoridades cena que envolvem a palavra, a música, a sonoplastia e os seus respectivos desenhos, além de uma tentativa de conscientização de suas peculiaridades para o desenvolvimento dessas em performance, objetivam entre outros, explicitar o elevado grau de importância, potência, complexidade e fluidez que podem constituir os sons na cena teatral contemporânea. Na experiência apresentada 4 que envolve 10 anos de docência, inúmeras orientações em trabalhos finais de graduação e pós-graduação e aproximadamente 25 experiências estéticas em que fiquei responsável pela produção sonora do espetáculo ou por parte desta, posso afirmar que este apoio conceitual têm sido de considerável valia em função de sua clareza, eficácia e possibilidade de abertura à propostas que não se enquadram facilmente em moldes pré-estabelecidos.

No entanto, cabe destacar que entre o início formal da pesquisa em 2004 até meados 2012 utilizava o termo entorno acústico como um equivalente à sonoplastia (LIGNELLI 2006a, 2006b, 2007, 2008, 2009a, 2009b, 2010, 2011a, 2011b, 2011c). Esta iniciativa se deu pelo fato das definições encontradas não incluírem possibilidades discursivas e dramáticas da sonoplastia que foram sinteticamente exemplificadas acima, e também, em função de as mesmas definições não considerarem que os sons ora presentes na cena, que não foram produzidos previamente para esta, mas que da perspectiva apre-

\footnotetext{
4 http://buscatextual.cnpq.br/buscatextual/visualizacv.do?id $=$ K4766033Y9
} 
sentada interferem na sua produção de sentido, merecem atenção e estratégias de relacionamento com estes sons por parte dos envolvidos no processo estético.

Acho relevante anunciar também que o retorno ao termo original sonoplastia (com uma redefinição que abarque as questões apresentadas acima) se deu a partir do questionamento de um estudante de graduação sobre a abrangência do entorno acústico que me despertou o desejo de repensar o conceito. A partir daí, após 8 anos estabilizado em uma terminologia, consegui enxergar que, apesar dos argumentos desenvolvidos, sonoplastia constitui-se em um termo mais preciso e claro para o que se pretende na cena, inclusive com relação à sua inerente referencialidade: do latim sono, som e grego. plastós, modelado. Para mim a relevância não se encontra estritamente no retorno ao termo em si, mas principalmente no fato de que uma pergunta gentil em sala de aula ter desestabilizado um conceito que parecia definido e confortável, me provocando a reconhecer a imprecisão da proposta, e então transformá-la em outra estabilizada aqui até um novo arrebatamento.

Defendo assim tanto a permanência de uma postura porosa do pesquisador, no sentido de se deixar atravessar pelas experiências, quanto a importância da longevidade de algumas pesquisas que requerem por vezes tempos de decantação para que possamos repensar, reformular e por que não retornar reformulando...

\section{Referências}

CAMARGO, Roberto Gil. A sonoplastia no teatro. Rio de Janeiro: Instituto de Artes Cênicas, 1986.

DAVINI, Silvia. O lado épico da cena ou a ética da palavra. Os trabalhos e os dias das artes cênicas: ensinar, fazer e pesquisar dança e teatro e suas relações. In: CONGRESSO BRASILEIRO DE PESQUISA E PÓS-GRADUAÇÃO EM ARTES CÊNICAS, 4., Rio de Janeiro. Anais... Rio de Janeiro: Sete Letras, 2006. p. 308-309.

LIGNELLI, César. Sons \& cenas: produção e apreensão de sentido a partir da dimensão acústica. Tese de Doutorado, Universidade de Brasília. 2011a.

.Una perspectiva de la dimensión acústica de la escena. Dossiê de Voz e Performance. Buenos Aires, 2011b. http://www.telondefondo.org/

A dimensão acústica de inútil canto e inútil pranto pelos anjos caído. Livro comemorativo dos 7 anos do Grupo Teatro do Concreto. Brasília, 2011c.

A palavra em performance na Poética e nos Problemas de Aristóteles. Som, Palavra e Performance, Revista do Programa de Pós-Graduação em Arte da UnB. Brasília, 2010a.

As esferas acústicas da cena por meio do cinema. Arte e ciência - abismo de rosas. In: CONGRESSO BRASILEIRO DE PESQUISA E PÓS-GRADUAÇÃO EM ARTES CÊNICAS. 6., São Paulo. Anais... São Paulo: UNESP, 2010b.

. Direito de ir... ou...vir. Cinema e educação: um espaço em aberto, ano 19, n. 4. 2009a Disponível em: http://www.tvbrasil.org.br/saltoparaofuturo 
. Considerações sobre a dimensão acústica nas aulas de teatro em contextos escolares. A pesquisa teórica e os processo criativos na cena contemporânea. In: REUNIÃO CIENTíFICA DA ABRACE. 5., São Paulo. Anais... São Paulo: USP, 2009b. Disponível em: http://www.portalabrace.org/vcongresso/ textosterritorios.html

Sonoplastia e/ou Entorno Acústico, seu lugar na cena teatral. Criação e Reflexão Crítica. In: CONGRESSO BRASILEIRO DE PESQUISA E PÓS-GRADUAÇÃO EM ARTES CÊNICAS, 5., Belo Horizonte. Anais... Belo Horizonte, 2008. Disponível em: http://www.portalabrace.org/vcongresso/textosterritorios. html

A produção de sentido a partir da dimensão acústica da cena: uma cartografia dos processos de composição de Santa Croce e de O Naufrágio. Dissertação de Mestrado, Universidade de Brasília, 2007.

'A dimensão acústica da cena no Teatro Ocidental', 'Os trabalhos e os dias' das artes cênicas: ensinar, fazer e pesquisar dança e teatro e suas relações. In: CONGRESSO BRASILEIRO DE PESQUISA E PÓS-GRADUAÇÃO EM ARTES CÊNICAS. 4., Rio de Janeiro. Anais... Rio de Janeiro: Sete Letras, 2006a. p. 262-263.

'A Construção de Sentido a partir da Dimensão Acústica da Cena'. Saberes e práticas antropológicas desafios para o século XXI. In: REUNIÃO BRASILEIRA DE ANTROPOLOGIA, 25., Goiânia. Anais... Goiânia, 2006b.

MICHEL, François. Enciclopédia Salvat de la Música. Barcelona: Salvat Editores, 1967.

SCHAFER, Murray. O ouvido pensante. São Paulo: Unesp,1991.

THE CONCISE OXFORD ENGLISH DICTIONARY. 4. Ed. 1956.

TRAGTENBERG, Lívio. Música de cena. São Paulo: Perspectiva, 1999. 